\title{
LXXXIII. THE $p_{\text {H }}$ OF THE GASTRO-INTESTINAL TRACT OF CERTAIN RODENTS USED IN FEEDING EXPERIMENTS, AND ITS POSSIBLE SIGNIFICANCE IN RICKETS.
}

\author{
BY THIRZA REDMAN, STANLEY GORDON WILLIMOTT \\ AND FRANK WOKES \\ From the Biochemical Laboratory, Cambridge, and the University of Liverpool.
}

(Received May 2nd, 192\%.)

Although determinations of the $p_{\mathrm{H}}$ of the contents of different parts of the gastro-intestinal tract have been carried out by many previous investigators on such widely different animals as human beings, dogs, cats, pigs, cows and sheep, very little attention appears to have been paid to the rodents so largely used in feeding tests for vitamins. This may be due in part to the greater difficulties involved in handling the minute quantities of material available in such small animals as guinea-pigs, rats and mice. But, in view of the fact that vitamins have already been shown in a number of cases to be affected by the reaction of the medium in which they are present, it seemed to us worth while to investigate the intestinal conditions in these particular rodents.

In the case of the albino rat and vitamin $D$, interest has been aroused by results recently published by several workers. Zucker and Matzner [1924], working on the faeces only, found that when rats were fed on a rachitogenic diet (Sherman and Pappenheimer's No. 84) the faeces became alkaline $\left(p_{\mathrm{H}} \cdot 7 \cdot 4-8 \cdot 0\right)$, and that administration of vitamin $\mathrm{D}$, either in the form of cod-liver oil, or by direct irradiation of the animals, was followed by a change, within a few days, to $p_{\mathrm{H}} 6 \cdot 0-6 \cdot 4$, although the rachitogenic diet was still continued. After administration of a vitamin D-free cotton-seed oil, this change in faecal reaction from alkalinity to acidity did not take place. These interesting results obtained by Zucker were confirmed by Jephcott and Bacharach [1926], who found that the change followed also after either direct irradiation of the animals or administration of irradiated cholesterol or of the vitamin $\mathrm{D}$ fraction of cod-liver oil (ostelin). The faeces, however, represent merely the end of the story. The absorption of calcium and phosphorus, which is closely connected with the rôle of vitamin $\mathrm{D}$, probably takes place mainly in parts of the gastrointestinal tract where the faecal condition has not yet been reached. It is, therefore, an obvious duty to compare the change in faecal reaction with any 
alterations which may simultaneously occur in the $p_{\mathrm{H}}$ of the entire gastrointestinal tract both on deprivation of vitamin $\mathrm{D}$, and on its readministration to rachitic animals.

An examination of the methods used by other workers indicated some of the obstacles to be expected. It was necessary to collect the material with all precautions possible in order to avoid contamination or undue exposure, and to examine it as soon as possible after the death of the animal. Diet, age, sex, time after last meal, and state of health of the experimental animal were amongst the factors to be considered. Whilst we have attempted to overcome all these difficulties, and numerous others which arose in the course of the work, we realise that the possibility still remains of some unknown factor having been overlooked, and would place this reservation on the results here recorded.

\section{ExperimentaL.}

\section{Collection of material.}

The animals were killed by chloroform. The abdomen was opened immediately, and the stomach ligatured at both ends. The oesophagus was cut above the ligature, and the large intestine just above the anus. The whole of the gastrointestinal tract was then removed and measured. Ligatures were applied at each end of the various sections of intestine whose $p_{\mathrm{H}}$ was to be determined. The stomach was rapidly washed with cold water, opened, and the whole of the contents removed and well mixed. A portion was quickly stirred with sufficient distilled water to make a liquid which could be poured into the electrode vessel; a small quantity was set aside for colorimetric estimation, and the remainder triturated with quinhydrone, poured into the electrode vessel, and the $p_{\mathbf{H}}$ determined as described below. The same procedure was adopted with each section of the tract examined, the principle being to avoid contamination by careful washing of the outside of the ligatured section, and to minimise exposure to the air by doing one section at a time, and transferring the mixed material to the closed electrode vessel as quickly as possible. In dealing with the material from the large intestine, when this was of too firm a consistency to mix readily by stirring, it was quickly broken down by rubbing on a glazed porcelain tile with a stiff spatula and just sufficient distilled water to make a thick liquid paste.

\section{Colorimetric estimation.}

Colorimetric estimations of the $p_{\mathbf{H}}$ of gastric and duodenal contents have been made by many workers, the methods adopted usually being modifications of Henderson and Palmer's [1912] original technique for estimating the $p_{\mathrm{H}}$ of urine, by comparing the colour given by the material or an aqueous extract on addition of a suitable indicator with the colour given to the same indicator by a standard buffer solution of known $p_{\mathrm{H}}$. In the case of urine, 


\section{$p_{\mathrm{H}}$ OF GASTRO-INTESTINAL TRACT OF RODENTS}

which is a fairly stable and well buffered fluid, it is moderately easy to obtain duplicate results agreeing to within $0 \cdot 1 p_{\mathrm{H}}$. When dealing with the contents of the stomach and intestines, however, a number of difficulties arise. In the first place, as has been shown by Kahn and Stokes [1926] in the case of the stomach, and by our own results throughout the gastro-intestinal tract, the material is not usually noticeably buffered until the ileum is reached. Since only minute amounts of material are available from the smaller animals, we were unable to apply Henderson and Palmer's method, which requires the use of a comparator, on account of the risk of dilution. Secondly, as Kahn and Stokes also showed, the most serious difference between colorimetric and electrometric results on gastric contents is due to loss of carbon dioxide, especially in faintly acid or alkaline solutions, and clearing the solution by centrifuging or filtering made very little improvement. Thirdly, there are the well-known protein and salt errors, which may be responsible for differences of 0.2 to $0.5 p_{\mathrm{H}}$, but are less serious than the loss of carbon dioxide. On the whole, these sources of error appear to diminish as the material passes down the gastro-intestinal tract, because we usually found widest divergence between colorimetric and electrometric results in the stomach, duodenum and jejunum, less in the ileum, and fairly close agreement in the caecum and large intestine. Our method of colorimetric estimation was as follows. About $0.05 \mathrm{~g}$. of the fresh material was taken up on a standard platinum loop, and mixed on a white glazed porcelain tile with about $0 \cdot 1 \mathrm{cc}$. of diluted indicator. If the material was too viscous, it was diluted with two or three times the quantity of distilled water immediately before taking the reading. The colour obtained was compared at once with those given by similar loopfuls of standard buffer solutions of known $p_{\mathrm{H}}$, mixed each with 1 drop of diluted indicator. The indicators used were thymol blue, bromophenol blue, methyl red, bromocresol purple, bromothymol blue, phenol red and cresol red, as recommended by Clark [1920], but further diluted to about $0.005 \%$. In every case a change of colour was used, and wherever possible readings were taken on the same sample with two or three different indicators. Duplicate results usually agreed to $0.2 p_{\mathrm{H}}$. The method requires the minimum amount of material and of dilution, and involves only a short time of exposure and loss of carbon dioxide. It gave the most satisfactory results in the caecum and large intestine, where the difference between colorimetric results in over a hundred samples was never more than $0.4 p_{\mathrm{H}}$, and averaged less than $0 \cdot 2$.

\section{Electrometric estimation.}

Electrometric estimations of the $p_{\mathrm{H}}$ in various parts of the small intestine have been carried out by several previous investigators on larger animals. McClendon [1915] and his co-workers, in their numerous experiments on men, cats and dogs, appear to have used generally a special type of hydrogen electrode, and quote results to $0 \cdot 1 p_{\mathrm{H}}$. Kahn and Stokes [1926], using a hydrogen electrode to measure the human gastric $p_{\mathrm{H}}$, claim to have secured an 
accuracy of $0.05 p_{\mathrm{H}}$. Long and Fenger [1917], working on material from the stomach and duodenum of men, and the jejunum and ileum of pigs, calves, lambs and a rabbit, and using a hydrogen electrode in a Hasselbalch vessel, quote $p_{\mathrm{H}}$ results to the second decimal place, but do not state what was their experience of the various possible sources of error. We have not been able to discover records of any $p_{\mathrm{H}}$ estimations on the caecum and large intestine. A great deal of work has been done on the faecal $p_{\mathrm{H}}$ in men and different animals. Robinson [1925] compared the results obtained with the hydrogen electrode and the quinhydrone electrode on a series of samples of faeces whose $p_{\mathrm{H}}$ ranged from $5 \cdot 0$ to $7 \cdot 8$, and found the difference to be $0 \cdot 0$ to $0 \cdot 3$, with an average of less than $0 \cdot 1$.

The quinhydrone electrode, since its introduction by Biilmann [1921], has been employed by a number of investigators, and found to give reliable results within the $p_{\mathrm{H}}$ range of 1 to 8 . The greatest advantages of the quinhydrone electrode over the hydrogen electrode for this particular work were:

(1) the rapidity and ease with which equilibrium is maintained, as compared with the time required, and difficulty of making readings, when using the hydrogen electrode;

(2) the consequent small loss of carbon dioxide, especially as a current of hydrogen is avoided, and a closed vessel can be used. Three types of electrode vessels were used, one designed by Corran [Corran and Lewis, 1924], and having a gold electrode, and two capillary vessels similar to those recently described by Cullen and Biilmann [1925] in which we used gold-plated platinum electrodes. The formula from which results were calculated was the following:

$$
p_{\mathrm{H}}=\frac{0.9802-(0.5600+E)}{0.058}
$$

$E$ being the observed E.M.F. of the following cell:

$\mathrm{Hg} / \mathrm{Hg}_{2} \mathrm{Cl}_{2} / M \mathrm{KCl} / \mathrm{Saturated} \mathrm{KCl} /$ Material saturated with quinhydrone/Au.

After making numerous parallel observations on different samples, we are of the opinion that our average experimental error with the quinhydrone electrode, which was used throughout this work, was less than $0 \cdot 1 p_{\mathrm{H}}$. Although in some of our tables the electrometric results are given to two places of decimals in order to show the variations obtained, we do not consider the second place significant. As will be seen later, a variation from the true $p_{\mathrm{H}}$ of less than $0 \cdot 1$ would not have any important effect on the conclusions to be drawn from our experimental work. When using the capillary electrode vessels, especially the straight tube type requiring only a few drops of liquid, diffusion was minimised by taking the reading as rapidly as possible, as suggested by Biilmann and Lund [1921].

\section{Experiments on guinea-pigs.}

Our first experiments were carried out on guinea-pigs, as it was thought advisable to gain experience on moderate-sized animals before turning to the 
smaller rats on which the bulk of the work was to be done. The results, however, may be of interest in connection with problems lying outside our own field of work, such as, for instance, the possible relationship between scurvy and acidosis [Lepper and Zilva, 1925].

The guinea-pigs used were normal animals, reared in the Bacteriological Department of the Liverpool City Laboratories. They were fed on a diet of bran, oats, cabbage and water ad lib., and were all in good health. A number of these animals were chloroformed at different times after their daily meal, the gastro-intestinal tract was removed as above described, and the $p_{\mathrm{H}}$ of its contents determined, colorimetrically and electrometrically, at various points throughout its course. It was found that the colorimetric and electrometric results agreed fairly closely (to within 0.2 or $0.3 p_{\mathrm{H}}$ ) when applied to the contents of the ileum, caecum and large intestine, but showed a wide divergence in the duodenum and jejunum, the colorimetric readings always being 0.3 to $1.5 p_{\mathrm{H}}$ higher than the corresponding electrometric readings. The colorimetric readings on the gastric contents were also higher than the electrometric, but the difference was not so great $\left(0 \cdot 2-1 \cdot 0 p_{\mathrm{H}}\right.$, average $\left.0 \cdot 5\right)$. This is in agreement with the results obtained by Kahn and Stokes [1926], working on human gastric material.

Table I. Comparison of results obtained by colorimetric and by electrometric methods for $p_{\mathrm{H}}$ of contents of gastro-intestinal tract of a normal guinea-pig.

Animal ô, 6 months old, killed 4 hours after meal.

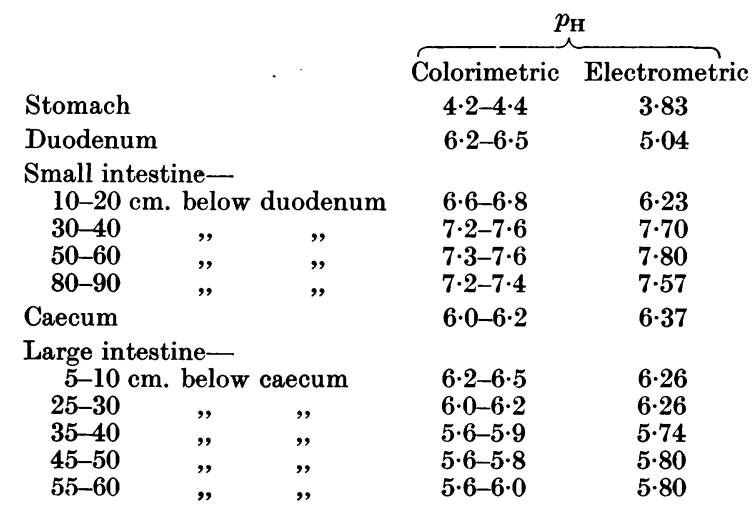

In Table I are given details of a typical example, in which estimations were made at as many points as possible. The figures given for the colorimetric results represent the extreme limits reached when each sample was tested with at least two different indicators, and were practically always obtained by independent observers unaware of the electrometric result. The electrometric readings were taken at first in a small electrode vessel whose capacity was about $2 \mathrm{cc}$. In order to obtain this quantity from the amount of intestinal material available, it was necessary to dilute the latter five to ten times. The 
question immediately arose as to what effect this would have on the $p_{\mathrm{H}}$. An experiment was therefore performed in which longer lengths of the intestine were taken, and sufficient of the contents obtained to make up a series of dilutions at each point. The results are shown in Table II, and from this and a number of similar experiments it would appear that the error due to dilution is greatest in the stomach, duodenum and ileum, and that the gastro-intestinal contents become more effectively buffered as one passes down the tract. On this account we decided to reduce the capacity of our electrode vessel, and after various trials we finally adopted the two types of capillary electrodes previously described, which enabled us to work with 1 in 3 or 1 in 2 dilutions. Judging from a large number of observations on this material in widely different dilutions, including some made with the Kerridge [1925] glass electrode, which permits the use of practically undiluted material, we are of the opinion that our electrometric results obtained with approximately 1 in 3 dilutions do not vary more than $0 \cdot 1$ to $0 \cdot 2$ from the actual $p_{\mathrm{H}}$ of these parts. In the caecum and large intestine the error is probably smaller. (The effect of dilution on the $p_{\mathrm{H}}$, determined colorimetrically and electrometrically, of faintly alkaline buffered solutions containing varying amounts of sodium chloride has been studied by Lepper and Martin [1926] who found changes of 0.05 to $0.2 p_{\mathrm{H}}$ when diluting four times.)

We next investigated the effect of chloroforming the animals at different times after the daily meal. Six guinea-pigs were examined, the period varying from $1 \frac{1}{2}$ to 17 hours, and the results obtained are summarised in Fig. 1. In plotting these results, the total length of the tract from stomach to anus was taken as a unit, and the various sections of the tract were expressed as fractions of that unit. This enabled an accurate comparison to be made of results obtained on animals of different sizes.

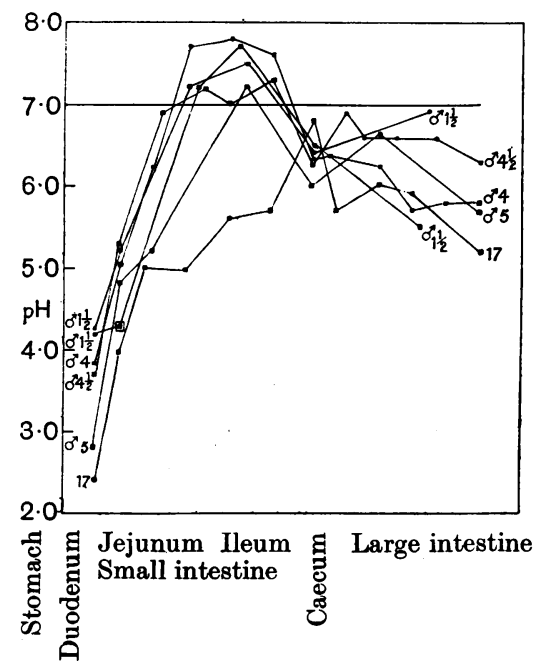

Fig. 1. $p_{\mathbf{H}}$ of gastro-intestinal tract of young normal guinea-pigs. 
Table II. Effect of dilution on the $p_{\mathrm{H}}$ of the contents of the gastro-intestinal tract of a normal guinea-pig.

Animal $\widehat{\alpha}, 7$ months old, killed $1 \frac{1}{2}$ hours after meal.

\begin{tabular}{|c|c|c|c|c|}
\hline & \multicolumn{4}{|c|}{$p_{\mathrm{H}}$} \\
\hline & \multirow{2}{*}{$\begin{array}{l}\text { Colorimetric } \\
\qquad 1 / 3\end{array}$} & \multicolumn{3}{|c|}{ Electrometric } \\
\hline Dilution & & $1 / 5$ & $1 / 50$ & $1 / 250$ \\
\hline Stomach & $4 \cdot 8-5 \cdot 2$ & $4 \cdot 26$ & $5 \cdot 04$ & - \\
\hline Duodenum & $5 \cdot 8-6 \cdot 2$ & $5 \cdot 22$ & $6 \cdot 62$ & $6 \cdot 52$ \\
\hline Small intestine- & & & & \\
\hline $\begin{array}{l}20-50 \mathrm{~cm} \text {. below duodenum } \\
50-80, ",\end{array}$ & $\begin{array}{l}6 \cdot 8-7 \cdot 2 \\
7 \cdot 4-7 \cdot 8\end{array}$ & $\begin{array}{l}7 \cdot 22 \\
7 \cdot 48\end{array}$ & $\begin{array}{l}6 \cdot 69 \\
6 \cdot 93\end{array}$ & $\begin{array}{l}6 \cdot 61 \\
6 \cdot 73\end{array}$ \\
\hline Caecum & $6 \cdot 2-6 \cdot 4$ & $6 \cdot 41$ & $6 \cdot 52$ & $6 \cdot 62$ \\
\hline $\begin{array}{l}\text { Large intestine-- } \\
\quad 30-35 \mathrm{~cm} \text {. below caecum }\end{array}$ & $6 \cdot 8-7 \cdot 0$ & $6 \cdot 93$ & $6 \cdot 62$ & $6 \cdot 52$ \\
\hline
\end{tabular}

In general, it was found that the acidity of the contents of the stomach and duodenum tends gradually to increase during the first 4 hours after ingestion of a meal, which is in agreement with the findings of McClendon [1915] on human subjects. In the remainder of the tract, however, no appreciable difference could be observed in the $p_{\mathrm{H}}$ results obtained when the time between feeding and death was anything between $1 \frac{1}{2}$ and $4 \frac{1}{2}$ hours. Only when food was withheld for as long as 17 hours was there a markedly greater acidity throughout the small intestine. Omitting this abnormal case, the results obtained on the other five animals may be summarised as follows: stomach $p_{\mathrm{H}} 2 \cdot 8-4 \cdot 3$, average $3 \cdot 8$; duodenum $4 \cdot 8-5 \cdot 3$, average $5 \cdot 1$; jejunum $5 \cdot 1-7 \cdot 1$; ileum $7 \cdot 0-7 \cdot 8$, average $7 \cdot 4$; caecum and large intestine $5 \cdot 2-6 \cdot 9$, average about $6 \cdot 4$. The stomach was always strongly acid, there was a decrease in acidity in the duodenum and ileum, so that the small intestine was mainly alkaline, and the caecum and large intestine, on the other hand, were always acid.

Another point investigated was the effect of entry of bile during dissection. In one animal the common duct was ligatured immediately after opening, and the duodenal contents were found to be more acid $\left(p_{\mathrm{H}} 4 \cdot 3\right)$ than in any of the other four animals. On adding to the duodenal contents $1 \mathrm{cc}$. of an aqueous extract (about $5 \%$ ) of the gall bladder, the $p_{\mathrm{H}}$ was raised to $5 \cdot 3$, the usual value in unligatured animals. These results indicated that the observed $p_{\mathrm{H}}$ of the gastro-intestinal tract might be appreciably affected either by the time of killing, or by the method of dissecting, the experimental animal. The method of killing usually adopted was by chloroforming, but in one or two cases where a blow on the head had been employed no appreciable difference was observed in the $p_{\mathrm{H}}$ results obtained.

\section{Experiments on rats.}

Having gained in the experiments on guinea-pigs some knowledge of the special difficulties involved, we next turned our attention to rats, on which the more important work was to be done. Both albinos (inbred from Wistar Institute ancestors) and piebalds were used, and gave similar results. The same technique was employed in preparing the experimental material, and in 
taking the colorimetric and electrometric readings. A discrepancy was again observed between the colorimetric and the electrometric readings in the duodenum and ileum. Undue dilution was avoided by the use of the capillary electrodes. The accuracy of these electrodes was tested by taking a number of parallel readings on material from different animals, and it was found that they gave results agreeing to $0 \cdot 2 p_{\mathrm{H}}$ or less, the average difference being below $0 \cdot 1$, as shown in Table III.

It was not possible to test the effect of cutting off the supply of bile, because the rat does not possess a gall bladder [Donaldson, 1924], and we were also unable to find the common duct. Whether this hitherto little recognised fact is associated with differences in the digestive processes is a problem for further investigation.

\section{Table III. Comparison of results obtained with the two types of capillary electrodes, on normal rats.}

\begin{tabular}{|c|c|c|c|c|}
\hline Animal & \multicolumn{2}{|c|}{$\begin{array}{l}\text { Albino } \\
\text { (12 months old) }\end{array}$} & \multicolumn{2}{|c|}{$\begin{array}{c}\text { Piebald } \\
\text { (2 months old) }\end{array}$} \\
\hline Electrode & Straight & Side-tube & $\begin{array}{l}\text { Straight } \\
p_{\mathbf{H}}\end{array}$ & Side-túbe \\
\hline Stomach & $3 \cdot 04$ & $3 \cdot 02$ & $3 \cdot 97$ & $3 \cdot 93$ \\
\hline Duodenum & $6 \cdot 11$ & $6 \cdot 11$ & $6 \cdot 49$ & $6 \cdot 49$ \\
\hline $\begin{array}{l}\text { Small intestine } \\
\text { Jejunum } \\
\text { Ileum }\end{array}$ & $\begin{array}{l}6 \cdot 31 \\
6 \cdot 59\end{array}$ & $\begin{array}{l}6 \cdot 50 \\
6 \cdot 79\end{array}$ & $\begin{array}{l}6 \cdot 62 \\
6 \cdot 29\end{array}$ & $\begin{array}{l}6 \cdot 48 \\
6 \cdot 31\end{array}$ \\
\hline Caecum & $6 \cdot 52$ & $6 \cdot 36$ & $6 \cdot 94$ & $7 \cdot 01$ \\
\hline Large intestine & $6 \cdot 50$ & $6 \cdot 61$ & $6 \cdot 88$ & $6 \cdot 99$ \\
\hline
\end{tabular}

We then carried out on albinos and piebalds a series of experiments similar to those previously done on guinea-pigs, in which normal animals on different normal diets were chloroformed at different periods after a meal, and the gastro-intestinal $p_{\mathrm{H}}$ determined. The diets fed varied from bread and milk to wheat, maize, oats and kitchen scraps (including greenstuffs), and contained adequate supplies of vitamins. Rats of different ages from 1 to 18 months were used. Typical results are shown in Fig. 2. The curve marked $K$ is plotted from results which, by courtesy of Prof. W. C. McC. Lewis, were kindly obtained for us by Dr Millet, using the Kerridge [1925] glass electrode. It will be seen that they agree closely with those obtained by our own method.

In the adult rats little difference was found when feeding these different normal diets. This failure to produce any marked alteration in the intestinal $p_{\mathrm{H}}$ by varying the protein/fat/carbohydrate ratios of normal diets is in agreement with the findings of Abrahamson and Miller [1925], who fed adult albino rats different diets, some consisting largely of carbohydrate (boiled potato), some mainly protein (lean beef), and some mainly fat (beef fat), and obtained on the average only a variation of $0 \cdot 1-0.2 p_{\mathrm{H}}$ in the stomach and small intestine. No results were given for the caecum and large intestine, and as their method was entirely colorimetric, the possibility of significant errors cannot be ignored. Their colorimetric results on a series of 36 animals were: stomach $2 \cdot 6-4 \cdot 1$, average $3 \cdot 9$; duodenum and jejunum $5 \cdot 2-6 \cdot 4$, average $5 \cdot 8$; 
ileum $5 \cdot 2-6 \cdot 0$, average $5 \cdot 8$. Our electrometric results on a series of 9 adult animals were: stomach $3 \cdot 0-5 \cdot 4$, average $4 \cdot 2$; duodenum $4 \cdot 0-5 \cdot 7$, average $5 \cdot 2$;

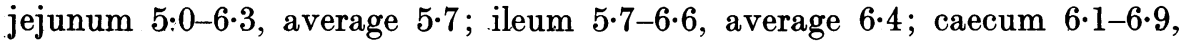
average $6 \cdot 4$; large intestine $6 \cdot 9-6 \cdot 9$, average $6 \cdot 4$. As in the guinea-pig, the effect of varying the time between last meal and death was most marked in the stomach, and appeared to produce little difference elsewhere.

Half a dozen young normal rats (4-12 weeks old) on different normal diets were also examined. Typical results are indicated in Fig. 2 by broken lines, the age of each animal also being given. (In order to avoid complicating the figures, only a certain number of typical animals are included.) It will be seen that in young rats the small intestine apparently tends to be more alkaline than in adults (jejunum $6 \cdot 5-7 \cdot 2$, average $6 \cdot 8$; ileum $6 \cdot 3-7 \cdot 6$, average $7 \cdot 0)$, but that the caecum and large intestine were always acid $(6 \cdot 5-6 \cdot 9$, average 6.7). From the recent work of Bergeim [1926] it appears that these last two sections of the gastro-intestinal tract are probably the most important in .regard to calcium metabolism and the action of vitamin $\mathrm{D}$.

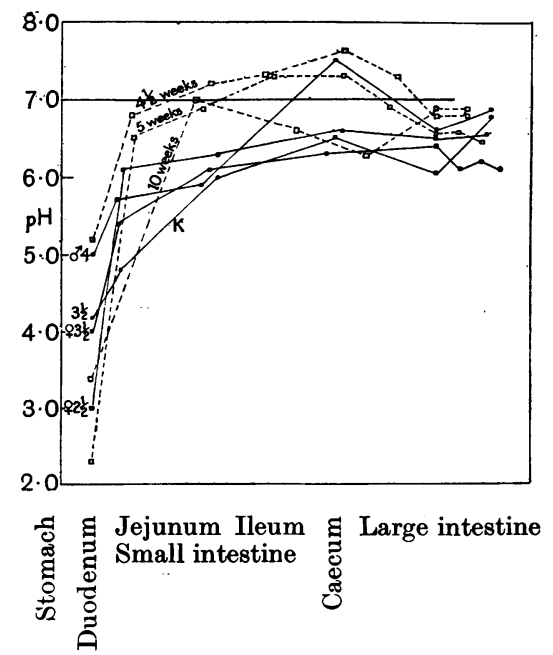

Fig. 2. $p_{\mathrm{H}}$ of gastro-intestinal tract of normal rats of different ages.

Young rats: - - - - - Adult rats:

The figure against each curve represents the number of hours between last meal and death.

Another question which arises is whether the $p_{\mathrm{H}}$ of the gastro-intestinal tract is in any way influenced by the nature of the intestinal bacterial flora. This problem has been carefully studied by Rettger and Cheplin [1921], working on both albino rats and human beings, and in both cases the conclusion was reached that the diet is the controlling factor. In regard to rickets, moreover, data obtained in experiments on dogs with various organisms isolated from the intestines of rachitic subjects would seem to render it unlikely that a bacteriological factor is predominant [Findlay, 1926]. It seemed to us that the fundamental fact to be investigated was the change in 
faecal $p_{\mathrm{H}}$ which Zucker has found to be produced by the action of vitamin $\mathrm{D}$, and, having found that in normal rats the $p_{H}$ in the caecum and large intestine was always below $7 \cdot 0$, we decided next to examine the effect of withholding this vitamin.

An examination of the diets used by various workers to produce experimental rickets in rats showed that these can be classified in two main groups, according to their content of carbohydrate and fat. One, which has been employed in America by Sherman and Pappenheimer, Zucker and others is noticeable for its high carbohydrate content (nearly $70 \%$ ), and especially for its very low proportion of fat (less than $3 \%$ ) (see Table IV). The other, which has been principally used by British workers, contains rather less carbohydrate (50-60\%), and much more fat (15-17\%), and resembles much more closely in general composition the natural diet of infants. Since all the experiments so far recorded on the reaction of the faeces in rickets have been done on rats receiving the first "low fat" type of diet, we thought it would be of interest to ascertain if the change of faecal reaction to alkaline would also be obtained on withholding vitamin D from rats on a "high fat" diet.

\begin{tabular}{|c|c|c|}
\hline & $\begin{array}{l}\text { "Low fat" " } \\
\text { type }\end{array}$ & $\begin{array}{l}\text { "High fat" } \\
\text { type }\end{array}$ \\
\hline $\begin{array}{l}\text { Carbohydrate- } \\
\text { Wheat starch (in flour) } \\
\text { Potato starch }\end{array}$ & 69 & $\overline{56}$ \\
\hline \multicolumn{3}{|l|}{ Protein- } \\
\hline $\begin{array}{l}\text { Egg albumin and wheat protein } \\
\text { Caseinogen }\end{array}$ & $21 \cdot 6$ & $\overline{23}$ \\
\hline \multicolumn{3}{|l|}{ Fat- } \\
\hline $\begin{array}{l}\text { Natural fat in wheat flour } \\
\text { Inactivated palm kernel oil }\end{array}$ & $1 \cdot 7$ & $\overline{17}$ \\
\hline \multicolumn{3}{|l|}{ Salts- } \\
\hline $\begin{array}{l}\text { Calcium lactate } \\
\text { Ferric citrate } \\
\text { Sodium chloride } \\
\text { Other minerals }\end{array}$ & $\begin{array}{c}2 \cdot 8 \\
2 \cdot 0 \\
2 \cdot 0 \\
\text { see note below }\end{array}$ & $\begin{array}{l}2 \cdot 7 \\
0 \cdot 2 \\
0 \cdot 2 \\
1 \cdot 9\end{array}$ \\
\hline & $99 \cdot 1$ & $99 \cdot 0$ \\
\hline
\end{tabular}

Some workers use wheat starch in their "high fat" diets.

In certain "low fat" diets the protein is partly supplied as gelatin and maize, and the fat content may be a little higher (between 2 and $3 \%$ ).

Palm kernel oil is replaced by inactivated cotton-seed oil in certain "high fat" diets.

Variable amounts of phosphates of calcium, magnesium and potassium, and traces of silica and other minerals are present in wheat flour. The "low fat" diets are usually noticeable for containing a high percentage of sodium chloride ( 1 to $2 \%$ ).

The above figures are calculated on dry materials.

Vitamin A is usually supplied as spinach.

Vitamin B in the "low fat" diets is present in the cereal.

Vitamin $\mathrm{C}$ in the "high fat" diets is supplied as lemon juice.

In most of the previous studies on experimental rickets no account has been taken of the differentiation of the fat-soluble vitamins, and the animals have been deprived of vitamin $A$ as well as of vitamin $D$. Chick and Roscoe [1926] appear to have been the first British workers to investigate the effect of depriving albino rats of vitamin $D$ only, vitamin $A$ being supplied daily in the form of fresh spring or early summer spinach leaves. The two diets 
used were of the "high fat" type (15 and $17 \%$ ), and had calcium/phosphorus ratios of $0.4: 1$ and $0.7: 1$ respectively. No record was made of the intestinal reaction or the faecal $p_{\mathrm{H}}$. Slight rickets was produced, the degree of calcification being nearer to normal than in animals also deprived of vitamin $A$. In these experiments, however, Chick and Roscoe were not always successful in avoiding xerophthalmia by the use of fresh. spinach leaves, although the daily dose in some cases reached nearly $3 \mathrm{~g}$. In view of these results, we decided to make certain modifications in Chick and Roscoe's technique when planning a similar investigation, in which the intestinal condition was also to be observed, and the relationship studied between faecal reaction and calcium and phosphorus retention. To ensure a satisfactory supply of vitamin $\mathbf{A}$, whilst avoiding unduly bulky doses of spinach leaves, we prepared an acetone-ether extract of freshly dried early summer spinach, and have up to the present been able to secure freedom from xerophthalmia in all our experimental animals by supplying this extract in $25 \mathrm{mg}$. daily doses as the sole source of vitamin A. Further tests which are being carried out appear to indicate that $50 \mathrm{or} 100 \mathrm{mg}$. doses of the extract do not contain significant amounts of vitamin $\mathrm{D}$. In addition to using this spinach extract in place of the fresh leaves, we have employed a "high fat" type of diet whose calcium/phosphorus ratio more closely approaches the value 1.6: 1 which is considered by McCollum [1923] to be approximately optimal for calcium absorption [cf. Willimott and Wokes, 1926, 1]. We hope to be able to publish later details of these studies.

The point of interest now is that when we had removed as far as possible all abnormal factors by supplying adequate amounts of vitamin $\mathbf{A}$, and by using a diet with a normal fat content and a practically normal calcium/phosphorus ratio, we have still found that deprivation of vitamin $\mathrm{D}^{\circ}$ produces an alkaline faecal reaction, which changes back to acid on restoration of the vitamin. Daily tests over a number of weeks on the vitamin D-free diet have given an average faecal $p_{\mathrm{H}}$ of $7 \cdot 3$, with fluctuations from $6 \cdot 5$ to $7 \cdot 8$.

In order to satisfy ourselves that the basal diet itself is not responsible for producing the alkaline condition, we have fed it to normal rats receiving adequate supplies of vitamins $A$ and $D$, vitamin $B$ being supplied in the form of a yeast extract, and have examined the intestinal reaction after different periods. The results, which are shown in Fig. 3, would seem to prove that the diet tends to produce in the gastro-intestinal tract a condition which is more acid than normal, probably on account of the type of salt mixture employed.

In regard to the faecal $p_{\mathrm{H}}$ in normal rats, it is of interest to note that Rettger and Cheplin [1921] when examining 146 samples from albinos on different diets, found them always acid.

We have also paid attention to the "low fat" type of diet. Thirteen different young albinos and piebalds which were fed this diet (see Table IV) developed a definitely alkaline faecal reaction $\left(p_{\mathrm{H}} 7 \cdot 3-8 \cdot 0\right)$ in 10 to 14 days. Three of these animals, when their faeces had remained at about $p_{\mathrm{H}} 8.0$ for at least a week, were chloroformed and examined. The results, which are 
shown as continuous lines in Fig. 4, indicate a definite tendency towards greater alkalinity throughout the tract. Even the stomach, after digestive activity had subsided, was only faintly acid $\left(p_{\mathrm{H}} 6 \cdot 1-6 \cdot 5\right)$. In one animal the most alkaline point reached was only $7 \cdot 2$, but in the other two a reading of 7.8 was recorded. At the lower end of the large intestine these two gave slightly higher readings $(7 \cdot 3$ and $7 \cdot 4)$ than the less alkaline animal (7.2), so that, judging by these three cases, the $p_{\mathrm{H}}$ of the faeces in rats on Zucker's diet would appear to give a fairly reliable indication of the conditions higher up the tract, in those parts where calcium absorption is probably most important. Abrahamson and Miller [1925], using colorimetric methods, also found that deprivation of vitamin $\mathrm{D}$ raised the $p_{\mathrm{H}}$ from $6 \cdot 0$ to $7 \cdot 0$ in the jejunum, and from 6.0 to $7 \cdot 1$ in the ileum. Unfortunately the colorimetric results were not checked by electrometric methods, and no readings were taken in the caecum or large intestine. On administration of cod-liver oil, however, the original acid condition was restored.

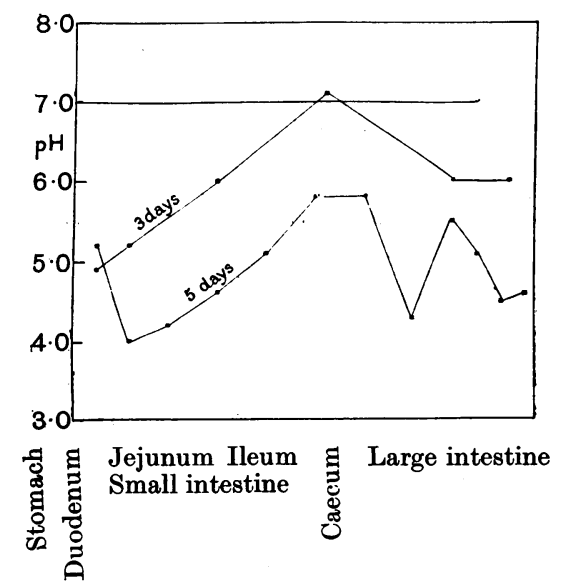

Fig. 3. Effect of "high fat" type of rachitogenic diet on $p_{\mathrm{H}}$ of gastro-intestinal tract of normal rats receiving vitamin $\mathrm{D}$.

Autopsies on our three rats did not reveal any marked signs of rickets, which was perhaps not surprising in view of the short period they had been on the rachitogenic diet. Microscopic and chemical examinations of bones from animals which have been kept on the diet for a longer period are now being made, and would appear to indicate the incipient stages of the disease. The condition of the animals is, in general, very similar to that which McCollum obtains in the preparatory period for his "line" test [McCollum, Simmonds, Shipley and Park, 1922].

On administering to the animals whose faecal $p_{\mathrm{H}}$ had remained at about 8.0 for 14 days vitamin D as cod-liver oil or as irradiated cholesterol, we found that the faecal $p_{\mathrm{H}}$ dropped gradually to about $6 \cdot 0$. The rate at which it drops seems to be influenced by the amount of vitamin D supplied, but if this is too large the faeces become very loose. In the case of four. animals which had 
been on exactly the same treatment, for the same period, administration of the same amount (about $0 \cdot 15 \mathrm{~g}$.) of a Norwegian oil brought the $p_{\mathrm{H}}$ down at approximately the same rate, the greatest variation in $p_{\mathrm{H}}$ of faeces (which were collected separately from each animal) on any day being 0.5 . Taking the faeces of any one animal on any given day, the greatest variation we have found in a number of samples is $0 \cdot 2$, and often it is much less. For this reason we suggest that an accuracy of $0 \cdot 1$ in the $p_{\mathrm{H}}$ determination is sufficient for the Zucker method.

We have also tested the effect of adding to the Zucker diet a well buffered natural food substance. For this purpose we used the freshly expressed juice of ripe Californian navel oranges (Sunkist brand). This had an average $p_{\mathbf{H}}$ of $4 \cdot 2$, and was so well buffered that 12 to $15 \mathrm{cc}$. of $N \mathrm{NaOH}$ were required to bring $100 \mathrm{cc}$. to $p_{\mathrm{H}} 7$. Four albino rats were put on a Zucker diet, and vitamin A was supplied as a daily ration of 2-3 g. fresh spinach leaves. When the faeces had been alkaline for over a week, each animal was then given a daily dose of 5 cc. of fresh orange juice. Since one of us had found this amount of juice to contain adequate amounts of vitamin $\mathbf{A}$ (unpublished data) the spinach was then discontinued.

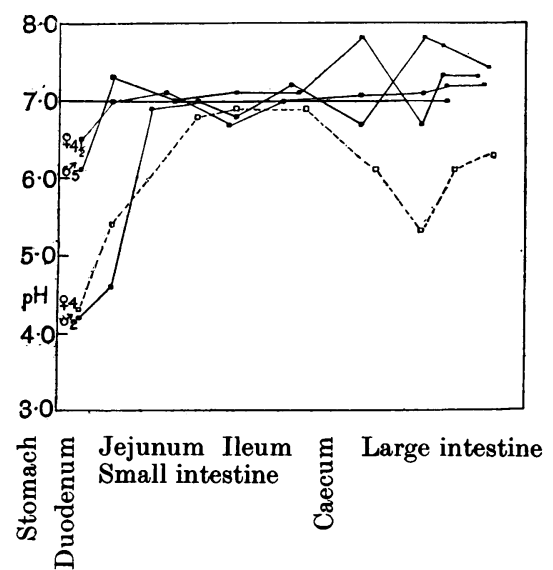

Fig. 4. Effect of vitamin $\mathrm{D}$ on $p_{\mathrm{H}}$ of gastro-intestinal tract of young albino rats on Zucker's "low fat" diet.

Rats on vitamin D-free diet:

Rats receiving D: - - $0---$.

The figure against each curve represents number of hours between last meal and death.

Daily readings taken for over a fortnight showed that the faecal $p_{\mathrm{H}}$ still remained alkaline $(7 \cdot 5-8 \cdot 0)$. Vitamin $D$ was then administered in two different ways, as irradiated cholesterol and as cod-liver oil, and in each case the faeces gradually became acid. One of the animals, when its faeces had been acid for 5 days, was then chloroformed and examined. The results, which are shown as broken lines in Fig. 4, indicate that administration of vitamin D had restored the acid condition throughout the gastro-intestinal tract. 
Experiments on other rodents.

Mice are not frequently used in feeding experiments on vitamins, although they were employed in the pioneer investigations of Stepp [1909]. Some white mice kindly supplied by Sir F. G. Hopkins were examined. The results would seem to show that the reaction in the gastro-intestinal tract of the white mouse on a bread and milk diet is similar to that of the rat, but somewhat more acid, the highest $p_{\mathrm{H}}$ recorded being under $6 \cdot 0$. The amounts of material available, however, were so small that the results are not considered sufficiently accurate for publication of details.

Rabbits have recently been used by Mellanby and Killick [1926] as experimental animals for the production of rickets, being fed on a basal diet of bran and oats, with turnip to supply vitamin C. We carried out an experiment on a young rabbit which had been fed on a diet of bran and oats, with cabbage to supply vitamins $A$ and $C$. The results, which are summarised in Fig. 5, resemble those previously obtained on the guinea-pig, another herbivorous animal.

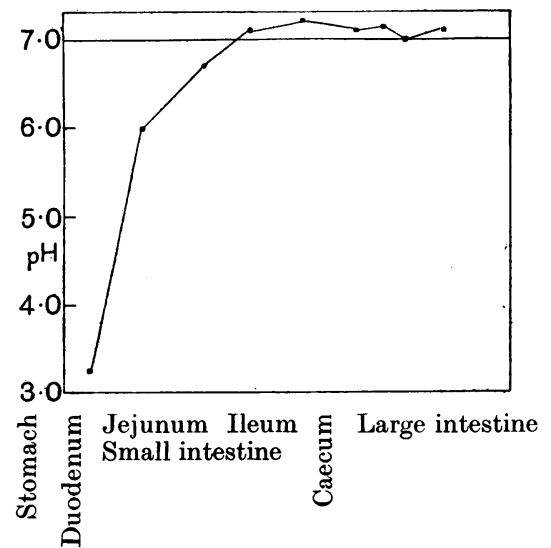

Fig. 5. $p_{\mathrm{H}}$ of the gastro-intestinal tract of a normal adult rabbit.

\section{Discussion.}

Although this investigation is in various respects incomplete, we think it desirable to mention certain points which may help to elucidate our experimental results, and perhaps indicate new lines of attack. Dealing first with the rat, on which the bulk of our work has been done, we have shown that deprivation of vitamin $\mathrm{D}$ produces in the gastro-intestinal tract a greater tendency towards alkalinity, and restoration of the vitamin brings the reaction back to acid. In the caecum and large intestine the difference between rats receiving vitamin $\mathrm{D}$, and those deprived of it, is even more marked, a change in $p_{\mathrm{H}}$ of such a small range as $6 \cdot 6$ to $7 \cdot 4$ appearing to be significant. Assuming for the moment that the incidence of rickets is influenced by the degree of calcium absorption in the intestines, it is obvious that this in turn will be subject to various factors which affect the solubility of calcium. Under normal 
conditions, the gastric hydrochloric acid probably is sufficient to render into soluble form practically the whole of the calcium in the food, as has been shown by Telfer [1924] in experiments both in vitro and in vivo, using dogs as subjects. As the food passes down the intestine, the gastric acidity tends to be more or less neutralised by the bile and other alkaline secretions, and calcium may be precipitated as carbonate, as soaps or as phosphates [cf. Willimott and Wokes, 1926, 2]. Blauberg [1900] has published analyses of the faeces of rachitic children, indicating that in rickets an abnormal amount of calcium is excreted in combination with phosphorus. Robison [1923] has demonstrated the presence in the wall of the small intestine in rats, guinea-pigs and rabbits of the phosphoric esterase which he suggests performs an essential part in calcification in the bones by liberating phosphate ions, and thus precipitating calcium phosphate. Robison and Soames [1924], using a preparation of this enzyme to hydrolyse different phosphoric esters, have shown that it has an optimum $p_{\mathrm{H}}$ range of $8 \cdot 4-9 \cdot 4$, and rapidly loses its activity as the $p_{\mathrm{H}}$ falls from $7 \cdot 5$ to $6 \cdot 8$. Provided that this enzyme is present in the intestine, the suggestion arises that the change in faecal and intestinal reaction from alkaline $\left(p_{\mathrm{H}} 7 \cdot 2-7 \cdot 8\right)$ to acid $\left(p_{\mathbf{H}} 6 \cdot 5-6 \cdot 8\right)$ which we have shown to occur in rachitic rats after administration of an antirachitic substance, may, by retarding the action of this phosphoric esterase, diminish the precipitation of calcium phosphate and thus facilitate calcium absorption from the intestines. If such is the case, then a metabolism experiment should show that the calcium retention is greatest when the faeces are acid, and least when they are alkaline, provided that the reaction of the faeces is a reliable indication of the $p_{\mathrm{H}}$ of the parts of the intestines most particularly concerned with calcium absorption and retention. In regard to the latter point, the recent results of Bergeim [1926] are significant. By means of experiments on rats, he found that on a rachitogenic diet the absorption of calcium is most seriously affected in the caecum and large intestine, where it might even become negative.

When vitamin $\mathrm{D}$ was administered in the form of cod-liver oil, at the level of 10 drops a day, the following increases were observed in the average percentage absorption of calcium: in the jejunum, an increase from 63 to 73 , in the ileum 35 to 57 , in the caecum nil to 50 , in the large intestine minus 5 to 80 . It is interesting to compare these results, which were obtained on a "low fat" type of diet, with the intestinal $p_{\mathrm{H}}$ we found in the three rats on the Zucker "low fat" rachitogenic diet. In all three cases the most alkaline point reached was not until the lower end of the small intestine, and in two cases there was only significant alkalinity $\left(p_{\mathbf{H}} 7 \cdot 2-7 \cdot 8\right)$ in the caecum and large intestine.

These results having led us to suppose that the faecal $p_{\mathrm{H}}$ can be considered a reliable indication of the intestinal reaction, we have set in train metabolism experiments in which the calcium and phosphorus retentions are being measured in rats fed different diets deficient in vitamin $\mathrm{D}$, and compared with daily variations in the faecal $p_{\mathrm{H}}$. We hope to be able to publish later details of our findings. 
In regard to guinea-pigs, the fact that we have shown that the greater portion of the small intestine is normally definitely alkaline $\left(p_{\mathrm{H}} 7 \cdot 2-7 \cdot 8\right)$, while the caecum and large intestine are acid $\left(p_{\mathrm{H}} 6 \cdot 8-5 \cdot 2\right)$, would seem to suggest that in this animal also a significant amount of calcium absorption takes place in the caecum and large intestine.

In regard to human beings, Flamini [1926] has recently reported results of experiments in which he found that the administration of vitamin $\mathrm{D}$ concentrate (ostelin) to rachitic babies was followed by a change in the reaction of the faeces from alkaline to acid, the "titratable acidity" for $100 \mathrm{cc}$. of faeces altering from $100-150$ cc. $N / 10 \mathrm{H}_{2} \mathrm{SO}_{4}$ to $100-300$ cc. $\mathrm{N} / 10 \mathrm{NaOH}$. Observations are now being made with the object of ascertaining if the reaction of the faeces in children can be correlated with the rachitic condition as it apparently can be in rats.

\section{SUMMARY.}

Colorimetric and electrometric methods for determining the $p_{\mathrm{H}}$ of the gastro-intestinal tract were examined, and an estimate made of the errors due to protein and salts, dilution and loss of $\mathrm{CO}_{2}$. A satisfactory technique was evolved using a capillary electrode vessel.

In guinea-pigs the following average $p_{\mathrm{H}}$ results were obtained: stomach $2 \cdot 8-4 \cdot 3$, average $3 \cdot 8$; duodenum $4 \cdot 8-5 \cdot 3$, average $5 \cdot 1$; jejunum $5 \cdot 1-7 \cdot 1$; ileum $7 \cdot 0-7 \cdot 9$, average $7 \cdot 4$; caecum and large intestine $5 \cdot 2-6 \cdot 9$, average about $6 \cdot 4$.

In normal adult rats (albinos and piebalds) the average figures were: stomach $4 \cdot 0$, duodenum $5 \cdot 5$, jejunum $6 \cdot 0$, ileum $6 \cdot 8$, caecum and large intestine 6.5 .

In rats 1-3 months old the average figures were: jejunum $6 \cdot 8$, ileum $7 \cdot 0$, caecum and large intestine $6 \cdot 7$.

A "high fat" type of rachitogenic diet when fed to rats gave greater acidity to the faeces and throughout the intestinal tract if vitamin $D$ was supplied, but in the absence of vitamin $D$ the faecal reaction became alkaline.

Rats fed on Zucker's "low fat" rachitogenic diet developed alkalinity throughout the intestinal tract, but especially in the caecum and large intestine (average $p_{\mathrm{H}} 7 \cdot 3$ ), which from Bergeim's work would appear to be the most significant areas in calcium absorption and retention. Administration of vitamin D as cod-liver oil or as irradiated cholesterol restored the acidity.

On account of increased buffering in the caecum and large intestine, the $p_{\mathrm{H}}$ of the faeces, which has been suggested as a criterion for the estimation of vitamin $\mathrm{D}$, would appear to be a reliable indication of the reaction in these sections of the gastro-intestinal tract, at least in the case of the rat.

Zucker's method for testing for vitamin $\mathrm{D}$ has been applied to a buffered natural food substance (orange juice).

The mouse and rabbit were also examined.

A possible relationship is discussed between the intestinal $p_{\mathrm{H}}$ and the occurrence of a phosphoric esterase in the aetiology of rickets. 
We are indebted to Sir F. G. Hopkins for his advice and interest in the work, to Prof. J. M. Beattie for laboratory facilities, and also for kindly diagnosing the condition of the animals, and to the scientific staff of Messrs Joseph Nathan and Co. for affording us free access to their experimental results.

A grant towards the expenses of the investigation was received from the Pharmaceutical Society of Great Britain.

Part of the work was done under the tenure of the Virol Research Scholarship in Clinical Pathology by one of us (T. R.).

\section{REFERENCES.}

Abrahamson and Miller (1925). Proc. Soc. Exp. Biol. Med. 22, 438.

Bergeim (1926). J. Biol. Chem. 70, 20.

Biilmann (1921). Ann. Chem. 15, 109.

Biilmann and Lund (1921). Ann. Chem. 16, 321.

Blauberg (1900). Z. Biol. 40, 1.

Chick and Roscoe (1926). Biochem. J. 20, 137.

Clark (1920). The determination of hydrogen ions.

Corran and Lewis (1924). Biochem. J. 18, 1358.

Cullen and Biilmann (1925). J. Biol. Chem. 64, 727.

Donaldson (1924). The rat (Philadelphia), p. 122.

Findlay (1926). Private communication.

Flamini (1926). La Pediatra, 34, 625.

Henderson and Palmer (1912). J. Biol. Chem. 13, 393.

Jephcott and Bacharach (1926). Biochem. J. 20, 1351.

Kahn and Stokes (1926). J. Biol. Chem. 69, 75.

Kerridge (1925). Biochem. J. 19, 611.

Lepper and Martin (1926). Biochem. J. 20, 45.

Lepper and Zilva (1925). Biochem. J. 19, 581.

Long and Fenger (1917). J. Amer. Chem. Soc. i, 39, 1278.

McClendon (1915). Amer. J. Physiol. 38, 180.

McCollum (1923). The Newer Knowledge of Nutrition. (New York.)

McCollum, Simmonds, Shipley and Park (1922). J. Biol. Chem. 51, 41.

Mellanby and Killick (1926). Biochem. J. 20, 902.

Rettger and Cheplin (1921). A treatise on the transformation of the intestinal flora. (Yale University Press.)

Robinson (1925). J. Biol. Chem. 66, 811.

Robison (1923). Biochem. J. 17, 286.

Robison and Soames (1924). Biochem. J. 18, 740.

Stepp (1909). Biochem. Z. 22, 452.

Telfer (1924). Quart. J. Med. 17, 245.

Willimott and Wokes $(1926,1)$. Pharm. J. Oct. 23, 495.

- $(1926,2)$. Pharm. J. Oct. 30, 521.

Zucker and Matzner (1924). Proc. Soc. Exp. Biol. Med. 21, 186. 